\title{
Teachers' Professional Development in Oman: Challenges, Efforts and Solutions
}

\author{
Mahfouda Juma Hamed Al Jabri \\ Specialized Centre for Professional Training of Teachers \\ Muscat, Oman \\ Heikki Silvennoinen \\ Centre for Research on Lifelong Learning and Education (CELE) \\ Department of Education, University of Turku \\ Turku, Finland \\ David Griffiths \\ Ministry of Education \\ Muscat, Oman
}

\begin{abstract}
Teachers' in-service training as such is not a new thing in Oman, but due to the national effort put in re-organising and systematising in-service training programmes in the past few years, a whole new phase has emerged in teacher professional development (TPD). The article describes how TPD is responding to the challenges of improving the quality of teaching and learning in Oman. The article also describes the tools used to examine the impact of the provided inservice training. Change in skills of teachers is necessary but not sufficient to make practices and pedagogies change. Results from interviews reveal that teachers encounter a variety of obstacles in schools when trying to make use of what they have learned in TPD programmes. Applying new skills and pedagogies often implies a radical change in established practices and ways of thinking in school culture with unquestionable elements due to long traditions.
\end{abstract}

Keywords: teacher education; teacher professional development; inservice training; educational reform; Oman.

\section{Introduction}

Education in the Sultanate of Oman has experienced a comprehensive transformation in the last four decades. In 1970 there were only three schools with 30 teachers provided education to a mere 900 boys. Girls were excluded from schooling. Currently, there are more than 1,068 schools, with 
approximately 46,610 teachers delivering twelve-year basic education to over 540,068 pupils in Oman, half of whom are girls (Ministry of Education 2016a). ${ }^{1}$

Throughout the 1970s, more than $90 \%$ of the teachers in Oman were expatriates. However, the Third National Development Plan which was introduced in 1980-1985, committed the Ministry of Education to gradually replace expatriate teachers with Omani nationals, and by 2010, $89 \%$ of the teachers were Omani. School administrators (school principals and their assistants) had almost completely been Omanised by 2010. (World Bank 2012; Ministry of Education 2016a.)

The development of educational infrastructure in Oman is exceptional compared to any country in the world. The World Bank described the education system progression in Oman as "massive" "unprecedented", and "unparalleled" by any other country (Ministry of Education 2008, 18). In 2010/11, education accounted for about $12 \%$ of Oman's total public expenditure, and education expenditure increased by $32 \%$ between 2009 and 2011, which is a substantial increase well in excess of inflation. The Ministry of Education is not only allocating substantial sums to education but is also evaluating development and reforms. In 2004, the ministry contracted an international institution to evaluate cycle 1 of basic education. In 2012, the ministry in cooperation with the World Bank, published a comprehensive review Drive for Quality (World Bank 2012).

Despite the achievements in initiating the comprehensive education system and expanding enrolment rates at all levels, the performance of students has remained disappointingly low. Four studies were conducted between 1993 and 2001 by The United Nations Children's Emergency Fund (UNICEF) in the Monitoring Learning Achievement (MLA) programme. In grades 4, 6, and 9 attainment levels were examined in Arabic, mathematics, science, and life skills, while in grade 10 pupils were evaluated in Arabic, Physics, Mathematics, Biology and Chemistry. The findings showed low students achievement in all subjects. Another study was carried out in 2003/04 with more than seven thousand grade 4 pupils being tested in English, Arabic, mathematics and science, and the findings indicated that students were on average approximately one year behind international standards. The results also revealed that there was a significant gender difference, with girls performing much better than boys. (Canedcom International 2004.) In 2007, Oman participated at grade 8 in the Trends in International Mathematics and Science Study (TIMSS) and in the 2011 study at grades 4 and 8 . The results showed Omani students performing well below the centre point of 500 in both subjects, and the test results deteriorated between 2007 and 2011. (Martin, Mullis, \& Foy 2008; Mullis, Martin, \& Foy 2008; Martin, Mullis, Foy, \& Stanco 2012; Mullis, Martin, Foy, \& Arora 2012.) As the Programme for International Reading and Literacy Study (PIRLS) from 2011 reveal,

1 The Sultanate of Oman is located in the south-east of the Arabian Peninsula. It has boundaries with Saudi Arabia in the east, Yemen in the South and the United Arab Emirates in the north. Oman is one of the largest countries in the Gulf Cooperation Council (GCC) (see Al Kharusi \& Atweh 2008). In 2014, the estimated population of Oman was 3.93 million. A large share of the population are foreigners, about 600,000 people, mostly guest workers from Egypt, Pakistan, India, Bangladesh, and the Philippines. (http://worldpopulationreview.com). On development of Oman since 1970, see e.g. Allen \& Rigsbee 2000; Looney 2009. 
results in literacy are not better than in mathematics. More than half (53\%) of Omani students failed to attain the basic reading level (the 'low' benchmark), while only $5 \%$ of the international sample and a mere $3 \%$ in Singapore and $1 \%$ in Hong Kong failed to reach this level. (Mullis, Martin, Foy, \& Drucker 2012; Al Shabibi \& Silvennoinen 2018.) The most recent results from TIMSS 2015 show a clear turn for the better in learning outcomes. However, the results of Omani students remain significantly lower than the average international level. (Mullis, Martin, Foy, \& Hooper 2016a, 2016b.)

Along with other countries in the Middle East and North African region, Omani schooling is facing problems, which make up an "educational crisis" in the country. A number of developing countries devote a relatively high expenditure to education and yet international assessments constantly show that only a minority of their young people are capable of reading, writing, and solving mathematical problems at a decent level (Pritchett 2013). Three converging factors characterise the educational crisis: (1) an increase in the educational disparity within countries, (2) a decrease in the quality of education despite high per capita education expenditures, and (3) a mismatch between labour market needs and the output of educational systems. (Chapman \& Miric 2009; United Nations 2002; see also Al Shabibi \& Silvennoinen 2018.) Especially the two latter features are the most acute and much discussed challenges in Oman. The simple conclusion in the World Bank report $(2012,84)$ was that "improving the quality of student learning should become the central focus of education policy". There is a consensus among education experts in Oman that teachers and pedagogies should be the primary targets of development measures. According to education administration measures are not only to be targeted to pre-service teacher education in colleges and universities, but also on in-service training and Teachers' Professional Development (TPD) in a wider sense.

TPD as such is not a new thing in Oman, but due to the national effort put in re-organising and systematising in-service training programmes for teachers in the past few years, a whole new phase has emerged in TPD. This article is the first study to focus on an analysis of the new system of TPD in Oman.

\section{Rational of the Study and Research Questions}

Reforming and restructuring the system of TPD is a corner stone in national efforts for improving teacher quality and leaning outcomes in Oman. Failings and weaknesses of Omani schooling have been thoroughly recognised and acknowledged in the national education policy (see e.g. Al Balushi \& Griffiths, 2013; Al Shabibi \& Silvennoinen 2018).

The focus of this article is on the new phase of teachers' professional development in Oman that began in 2014 when the Specialised Centre for Professional Training of Teachers (SCPPT) was initiated. The paper is descriptive in nature. It describes how TPD is responding to the challenge of improving the quality of teaching and learning in Oman. The paper also describes the tools used to examine the impact of the given in-service training. Some results on 
teachers' practice and students' attainment emphasise factors that help teachers to implement their new practice. The challenges they face will also be presented.

The aim of the article are to:

(1) describe the change in the present day TPD in Oman,

(2) identify how the challenges faced by teachers and Omani schooling are addressed by the measures taken to develop teachers' professional competencies, and

(3) describe the methods and tools used to examine the impact of the provided in-service training.

The study is grounded on various types of data and documents on the present day in-service training. SCPTT continuously gathers data from programme participants with questionnaires and interviews. In the following, statistical data and descriptive documents on in-service training programmes are analysed. Interview data on impact of training and implementation of the acquired skills are used as well.

\section{Theoretical and Contextual Background}

The present-day national education policy in Oman aims at bringing about improvements in all areas and at all grade levels within the education system. The quality of teachers is generally regarded as one of the most significant factor influencing on student learning achievement. There are various ways of improving the quality of teachers and teaching. In the case of Oman, probably the most effective ways would be: (1) developing and modernising initial teacher preparation, (2) selecting the most talented and motivated young people to be prepared as teachers, and (3) expanding, systematising and updating professional development for teachers.

The best results would be achieved when all three of these measures of improvement are implemented simultaneously. It is not an easy task to do, though. For example, attracting the best students to teacher education depends on factors that cannot be affected by educational policy measures only. The most crucial factor is the status afforded to the teacher profession by society. If the status of the profession is low, it is highly unlikely that the most talented students will choose it as their lifelong career. The status of the profession is dependent on a number of historical, cultural and economic factors, which cannot be affected by educational reforms alone. However, probably the fastest way to improve teachers' pedagogical skills and teaching quality is through professional development and systematised in-service training. Considerable national effort has been given to in-service training and professional development of teachers recently in Oman and these developments are worth scrutinising in more detail.

As part of the overall reform process for improving education, the Ministry of Education of Oman launched a national project to raise the standards of teachers' professional development (Ministry of Education 2009). In short, the goal of professional development of teachers is to change classrooms practices, pedagogical thinking, values and attitudes of teachers in order to raise learning outcomes of students (Griffin 1983; Guskey 2002). Moreover, 
professional development is crucial for all those who interact with youth, as it captures the challenges and develops opportunities of future citizens and labour power (Weiss 2006).

Despite the massive development of the Omani education system, there are several problems in schooling, which all are part of the reason behind the slow improvement of learning outcomes. One of the biggest problems with the quality of teachers is the heterogeneity of teachers in terms of their initial preparation and their dedication to the teacher profession. The institute with the highest status in the field of teacher preparation is the College of Education at Sultan Qaboos University (SQU). However, only about $15 \%$ of newly qualified teachers graduated from SQU. The rest come from private Omani institutions with variable standards and institutions abroad. As the World Bank Report (2012) says, it is a commonly known fact in Oman that the level of subject knowledge and teaching skills of a newly qualified teacher much depends on the institution from which he or she has graduated. Another problem with the new teaching force is that many student teachers are not strongly motivated and committed to be teachers. Teacher education serves them as a second or third option in higher education due to lack of career alternatives. Unmotivated and uncommitted teachers are a big challenge for professional development and inservice training (e.g. Ryan \& Deci 2000). How to encourage young teachers to develop themselves professionally when they feel no real interest in working in teaching profession in the first place remains a significant issue.

The quality of teaching depends on the college that delivers the teaching programme, the teachers' motivation and commitment towards the teaching profession and their experience. Thus, teachers' preparation affects students' learning outcomes and the quality of the entire education system. The World Bank (2012) states that the fact that Omani teachers lack intrinsic motivation is a big concern to the education administration. (Wyatt 2013.) Compared to the other colleges, the SQU graduates are considered to be the best, although even here the relevance of its preparation courses has raised concerns. Teachers continue to practice didactic teacher-centred approaches rather interactive leaner-based approaches. For instance, educational supervisors' field visits discovered that teachers rarely use different teaching approaches when addressing students' individual differences in achievement levels. One factor which may help to explain this relates to teacher experience in dealing with such learners. Research data show that $65 \%$ of Omani teachers have less than 10 years of teaching experience. Additionally, many display poor knowledge of the syllabus and of how to use the latest instructive tools and associated technology. (World Bank 2012.)

Newly qualified teachers typically face problems in several areas of their work. They are not sufficiently prepared for classroom management, on how to motivate students, how to use a variety of assessment methods, and how to accommodate individual differences in the class (World Bank 2012). A research by Al Shabibi (2013) reveals that one of the key problems faced by newly qualified Omani teachers is "a reality shock": young teachers are not capable of coping with classroom management and the unexpected workload. Teacher preparation in Oman is excessively theoretical in content, and during their studies teacher students are not given adequate practical tools to cope with 
everyday life in the classroom. In addition, as Al Shabibi and Silvennoinen (2018) say, "the current curriculum is over-crowded in terms of the content expected to be covered within the time available and heavily prescribed in terms of what is to be delivered and the means of delivery" (see also World Bank 2012; New Zealand Education Consortium 2012).

Teachers need much more sophisticated set of skills to be able to respond to the demands for individualised learning of pupils with different levels of ability. Teachers lack the skills for assessing the strengths and weaknesses of each individual pupil they teach (cf. Jones 2005). They also lack the skills for selecting appropriate instructional methods in order to help pupils to learn the way that is suitable for their individual ways of learning. (Ministry of Education 2016b.)

There is a structural problem in Omani education policy as teacher preparation and basic education (for which the teachers are trained) are divided between two ministries. The Ministry of Education is responsible for education from kindergarten to grade 12. Schools are responsible for implementing the ministry's policies on the curriculum and textbooks, assessment, teachers' qualifications, school staffing levels, teachers work obligations and distribution of financial resources (Ministry of Education 2008). The Ministry of Education is also responsible for the in-service training of teachers, but has no responsibility for pre-service teacher training. Teacher preparation is governed and administered by the Ministry of Higher Education (MoHE). This kind of governance structure demands continuous open interaction between the two ministries, since being entrenched in their own bureaucracies is counterproductive for the common good. Salma Al-Lamki (2002, 83) has described the administrative situation of education in the following way: "The current system of higher education in the Sultanate of Oman is managed by a number of ministries and government bodies. This creates competition for resources and limits consensus on system-wide approaches for improving accessibility, quality and performance. Consequently, this breeds duplication of administrative and financial resources."

In previous decades, TPD in Oman was organised by the Ministry of Education as short In-service Education and Training (INSET) courses. Besides formal training courses, the INSET included workshops and conferences. An important characteristic of INSET was that it was a top-down procedure in which decision makers were also the organisers and the planners of training. In the General Education System (prior to 1998), teachers' professional development was achieved through two ways: by short in-service training courses and the school inspection system. The training courses were mainly delivered in the regions, particularly in the schools, although some programmes for English teachers were conducted centrally. Additionally, inspectors usually provided direct support and feedback to teachers during the inspection visits. According to Al-Lamki (2009), TPD was not only traditional but was narrow and lacked logic. Later on, the term Continuous Professional Development (CPD) has emerged with a broader idea of systematic professional development ( $\mathrm{Al}$ Lamki 2009).

The new basic education system (grades 1-10) was introduced in 1998, and the reform also covered professional development of teachers in two areas: 
TPD was organised for all the ministry's employees, and teachers' knowledge, skills and qualifications were being more systematically upgraded. However, TPD activities - especially the formal ones - were still being planned and monitored at a ministry level through the departments of supervision and curriculum, i.e. the training and supervision model remained a top-down model (Al Lamki 2009). The Ministry of Education provided professional development courses with training organised through "a cascade approach". This involved identifying trainers in the regions, training them centrally, and then instructing them to return to their regions to replicate the training programmes with all teachers. (World Bank 2012.)

\section{New Phase of TPD in Oman}

As mentioned above, there have been two deficiencies with teacher education: teacher preparation does not produce the skills required for the teacher profession, and in-service training has been sporadic and poorly planned. In an attempt to meet the challenge of the heterogeneous quality of newly qualified teachers, and the need to bring about fundamental change in classrooms, the Specialised Centre for Professional Training of Teachers (SCPTT) was established. SCPTT is nationally responsible for the training of teachers and other education professionals in the Sultanate. The establishment of the centre is an integral part of the policy, which also includes the establishment of the National Centre for Careers Guidance, the Centre for Educational Evaluation and the National Assessment Centre. These national centres aim to attract the best talent and expertise through granting them a degree of independence regarding recruitment, administrative and financial affairs.

\subsection{Organisation and Programmes of the New TPD}

The aim of the Specialised Centre for Professional Training of Teachers (later in the text SCPTT or the Specialised Centre) is to build a critical mass of teachers, school principals and supervisors who believe in, and practice, the methods and approaches required to raise student attainment (see The Education Council 2012 , 41). In Oman, TPD is not only about skills - skilled teachers also need to become committed to their profession, and committed to enabling their pupils to achieve their full potential in learning.

In Oman, all teachers have to obtain a university degree in education or a university degree with a diploma in education. Furthermore, teachers must pass a test and an interview before being appointed. Additionally, SCPPT has been established to set professional standards for the teaching profession. SCPPT has commenced procedures to issue licences when teachers meet the criteria. ${ }^{2}$ (Ministry of Education 2014.)

2 The Centre follows the Ministry of Higher Education National Qualifications Framework to licence the programmes and it issues certificates under a University College of London (UCL) endorsement process. The centre's programmes are level 6 graduate diploma, are worthy of credits within the QAA Framework for Higher Education Qualifications (FHEQ) of UCL and that is equivalent to level 5 of the Oman's National Framework granted by the MoHE. After the standardisation and moderation processes have been completed by both parties (Oman and the UK), a 
SCPTT began its work with the careful selection and training of trainers to ensure that they had sufficient theoretical and practical experience to be effective instructors. The Centre was officially opened in 2014 in an adapted temporary building, which includes 56 training classrooms, a library, a science laboratory and meeting rooms. SCPTT began operating with a staff of approximately 100 people and with 1,000 teachers participating in programmes each day. At full capacity, up to 2,000 new teachers, 6,000 experienced teachers and 1,000 educational leaders and supervisors will follow the Centre's strategic programmes yearly.

The priorities for the selection of the first programmes introduced by SCPTT were to support basic learning in reading, writing and mathematics, subjects which are important to the future of the Omani economy, and which form the basis of comparisons in student performance in international evaluations.

To secure direct impact on student standards, and to bring about the required changes in schools, all SCPTT programmes are meant to be:

- comprehensive (a high proportion of teachers/supervisors from selected subjects/specialisms and participation from all schools),

- sustained (two-year programmes to provide time to embed knowledge, skills and attitudes),

- integrated (face-to-face training using a wide range of active learning methods; online learning to enable participants to engage with the Centre whilst in the workplace - all participants are provided with a laptop and connectivity for use throughout the programme; and workplace training to provide practical opportunities to develop skills and embed practice),

- accredited (by a qualification from an internationally recognised university or authority, and allowing for credit accumulation leading to the award of higher degrees as teachers progress through their careers), and

- supported (through ongoing contact, monitoring and evaluation by trainers).

Training in the Specialised Centre has three main components: face-to-face teaching, online learning and workplace learning. Face-to-face teaching involves small group teaching, collaborative learning sessions, and problem solving activities, with the objective of changing teaching practice. Online learning primarily consists of Wikis and online forums that encourage collaboration and discourse to evaluate innovative teaching methods. Workplace learning implements and evaluates changes in teaching and learning practice through an evidence-based approach.

Starting from March 2014, SCPTT's two-year professional development programmes commenced operation for 2,700 teachers. The Diploma programmes offered by SCPTT are:

certificate will be issued to the participants on the successful completion of four modules in each programme. In short, following UCL's endorsement of four programmes, the MoHE has to approve the programmes in order to issue the diploma certificates. 
1. Senior Teachers Programme targets one senior teacher from each school in the Sultanate. It provides them with up-to-date techniques in learning, teaching and evaluating. It also provides advice and guidance on how to help develop other teachers. The programme places a heavy emphasis on collaborative consultation and development with colleagues in their school. It clarifies the responsibility of teachers to transform the quality of learning in their schools.

2. Arabic Experts Programme (grades 1-4) is delivered to at least one experienced teacher of Arabic in every grade 1-4 school to provide them with effective educational strategies and methods on how to integrate the teaching of the four skills of language learning.

3. Mathematics Experts Programme (grades 5-10) targets one experienced maths teacher in every grade 5-10 school. It provides them with studentcentred learning techniques, research methods and the application of mathematical concepts.

4. Science Experts Programme (grades 5-10) is delivered to one experienced science teacher in every grade 5-10 school. It provides them with investigative learning techniques, research methods and the application of scientific concepts.

5. Expert Supervisors Programme targets about one-third of the educational subject supervisors to enhance their skills in supervising and developing teachers. The programme also fully updates the supervisors about the methods and strategies being developed in other programmes so that they can share improvements across the schools with which they work.

6. School Leaders Programme targets school leaders and their deputies in Oman's government schools. The overall aim of the programme is to strengthen their roles as leaders of learning in their schools. The six sections in the programme build on the expertise and professional learning the school leaders already have, and are designed to promote a deeper level of understanding and application. The programme includes an extended school improvement task undertaken in collaboration with 3 or 4 other participants, all of whom focus on a common area. The task is being recorded as both a research thesis and a contribution to a National library of good practice and resources to share.

7. New Teachers Programme targets all newly appointed teachers in Omani government schools. The programme aims to enhance new teachers' knowledge, skills and attitudes towards teaching and provides them with the support they need at the beginning of their careers. It focuses on constructivist methods; inquiry based learning and creative approaches to teaching.

All programmes have been developed around a set of professional standards built on three broad areas: (1) professional attitudes and values; (2) professional knowledge and understanding, and (3) professional skills. The standards are described at four levels: 'poor', 'standard', 'good' and 'outstanding'. All the programmes focus on practical implementation of new methods and strategies, underpinned by an adequate understanding of the research and rationale 
behind them. Workplace learning tasks have specific requirements for classroom practice, evaluation and sharing experiences with colleagues.

\subsection{Monitoring and Research of In-service Training}

One crucial element that differentiates the new and the old system of teacher professional development is monitoring of the in-service training programmes. Continuous data collection and analyses are used to monitor the experiences of the trainees and the impact of the programmes. Evaluation is regarded as a fundamental part of decision-making and the basis for evidence-based policy (see e.g. Alexander 2002; Goode, Kingston, Grant, \& Munson 2010; Harrison 2003). Research is organised in two "streams": (1) analyses based on ROI (Return on Investment) methodology, and (2) studies on changing topics targeted to various stakeholders such as pupils, teachers, principals, parents and communities (see figure 1).

Philips and Philips $(2007,2)$ have described ROI as "a comprehensive measurement and evaluation process that represent the most promising, logical, and rational approach to show accountability". The ROI approach has five systematic levels; reaction, learning, application, impact and return on investment. The research actions, which are currently being undertaken by SCPTT, adopt the ROI methodology by placing emphasis on the quality assurance and evaluation of the Centre's activities. The quality assurance and evaluation unit has established operations in levels 1-3: (1) reaction and planned action, (2) learning and confidence, and (3) application and implementation. For the impact level, a mixed method quantitative and qualitative research approach is followed through student questionnaires, classroom observation, semistructured interviews for school leaders and teacher self-assessment forms.

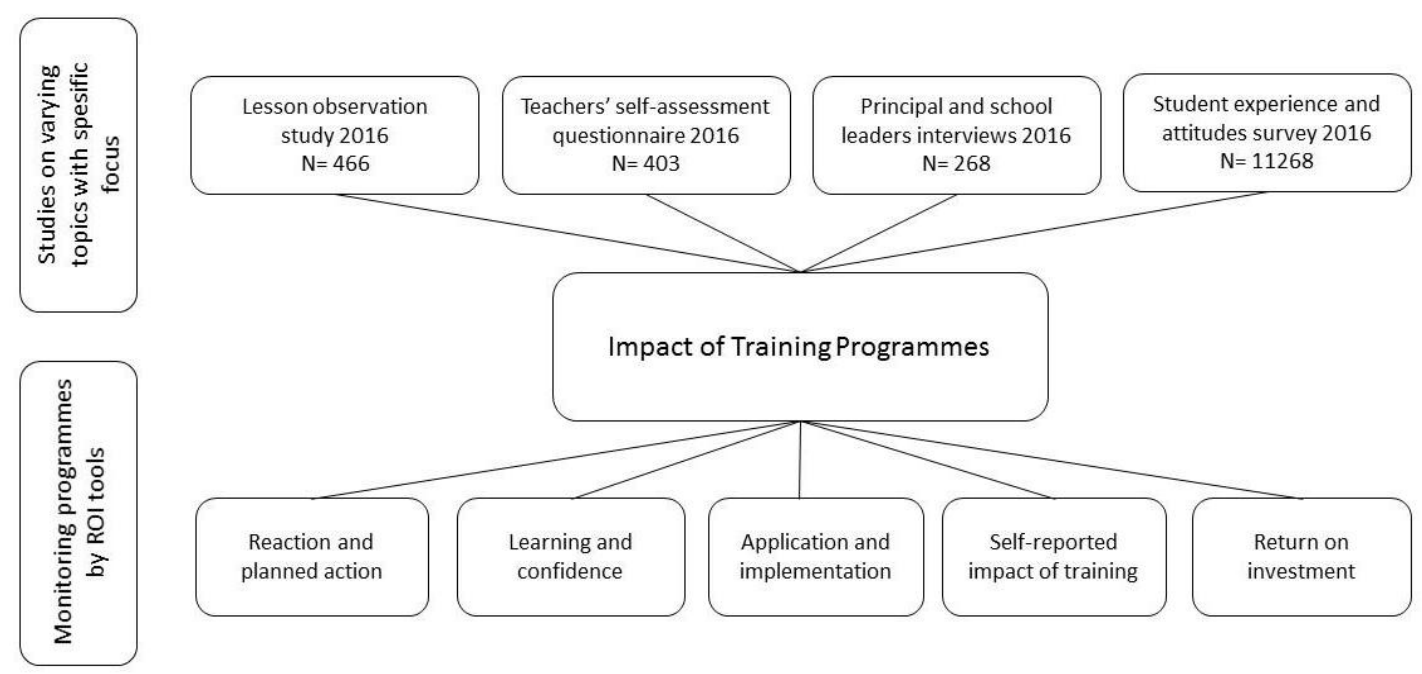

Figure 1: Methods for Examining the Impact of In-Service Training Programmes in SCPTT 
Besides using the ROI approach, several survey studies are conducted to examine the impact of the programmes on teacher behaviour. The first wave of large data collection was conducted in 2016 with the aim to examine (1) the impact of the training on the professional skills and attitudes of trained teachers, (2) the effects the trained teachers have on (a) teaching and learning methods used in their school, (b) the school community at large and the school environment, (c) on students' experiences and attitudes. All these four data sets have been collected in a way that enables them to be linked together, e.g. lesson observations with teachers' self-assessment and student experience and attitude survey data. The linking of the data collected by different methods is used also for validation purposes.

The mixed method approach used to investigate the topic combines quantitative and qualitative methods, using lesson observation of trained and non-trained teachers, interviewing school principals, conducting questionnaires with students of trained and non-trained teachers (see e.g. Gray 2011). Teachers also completed a self-assessment questionnaire with 130 items on skills and competences, impact of the training, possibilities and barriers of applying new teaching methods, and needs for further training. Quantitative methods can help to recognise links between variables and provide an overview of relevant associations, while a qualitative approach is useful in analysing concrete cases. According to De Leon and Chough (2013), a mixed method approach is used to increase reliability of the data collected, and to enhance the accuracy of findings (Kelle \& Erzberger 2001). Furthermore, the use of both approaches allows the researcher to combine the strengths and limit the weaknesses of each method (Punch, 2009).

\section{Results from Monitoring}

SCPTT assesses its programmes and monitors participants' performance according to the ROI methodology. In this section, we will look at responses from participants who joined the programmes in March 2014 and who graduated in February 2017.

Examining reactions and learning levels is conducted at the end of each training week focusing on face-to-face training (this ranges between 20 to 30 days during each two-year programme). The reactions and learning levels are assessed through four main axis, i.e. administrative organisation, programme content (incl. training materials), trainers and learning. The results in figure 2 show participants' high satisfaction to their trainers. The satisfaction to administrative organisation and programme content is a bit lower. The experienced learning percentages vary from 90 to 98 . 


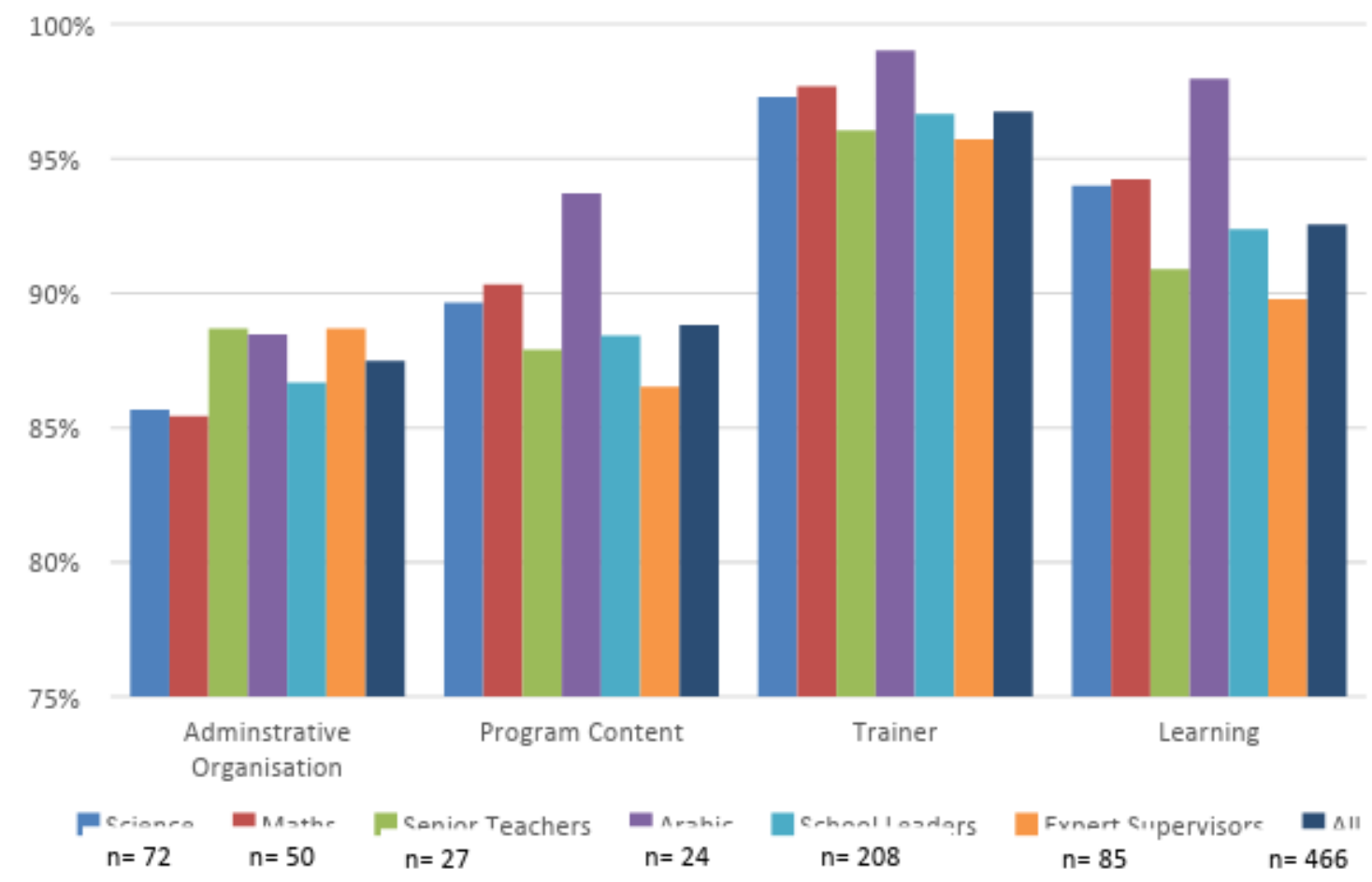

Figure 2: Participants' satisfaction to administrative organisation, program contents, trainer, and learning concerning the training received, by training program (\%)

Participants especially value the face-to-face training sessions, which they consider as professional learning communities. The fact that participants from all the eleven educational governorates of the country are gathered in same room provides a valuable opportunity to exchange ideas and learn from peers. The trainers assess their trainees during these sessions through participants' contribution to the training activities, the design and delivery of workshops and leadership and participation in professional debates. Furthermore, trainers monitor participant teachers' professional development throughout their journey by tracking their progress using professional qualities and values, which is based on three important criteria: enthusiasm and commitment, collaborative behaviour, and independence and initiative. The participants are evaluated by formative assessment methods, with trainers evaluating the participants' present level of skills and offering guidance on what they need to do to reach the desired outcomes. Participants are also assessed through tailored face-to-face, online and workplace assignments. Participants are given time to answer them and to implement them in their schools collaboratively with colleagues.

SCPPT has established a learning platform for participants to communicate through professional dialogues on forums and educational contributions on Wikis. Participants are required to undertake tasks, and are provided with readings and research articles to help bridge theory with practice. Trainers monitor their trainees' progress and their application of acquired knowledge through their dialogues and conversations with colleagues. Through some practical tasks, the participants are expected to apply what they learnt in the face-to-face and online learning in their workplace. To help them plan their tasks, participants are released from duties one day per week. Trainers visit 
participants in schools to offer support. At the end of that period, the participants are required to write an academic report (case study or an action research) where they can link the theory to their practice. (Ministry of Education 2014.)

The analysis on reaction does not show any significant gender differences in reaction as male and female teachers are trained under the same circumstances in the Centre. However the passing rates differ considerably by gender, as show in figure 3. All of the Centre's programmes target female and male teachers, with the exception of the Arabic programme (grades 1-4) which is taught in schools by female teachers only. The pass rates in the programmes reflect the gendered reality in schools and in the teacher profession in Oman. The gender difference seen in figure 3 is in line with other observations in teacher profession in Oman.

The Arabic programme has the highest pass rate, and female participants have a higher pass rate than males in all of the other programmes. Especially male supervisors fail to pass the training along with their female colleagues. The figures indicate substantial gender differences suggesting that female teachers are more dedicated to the professional and academic assignments in professional development.

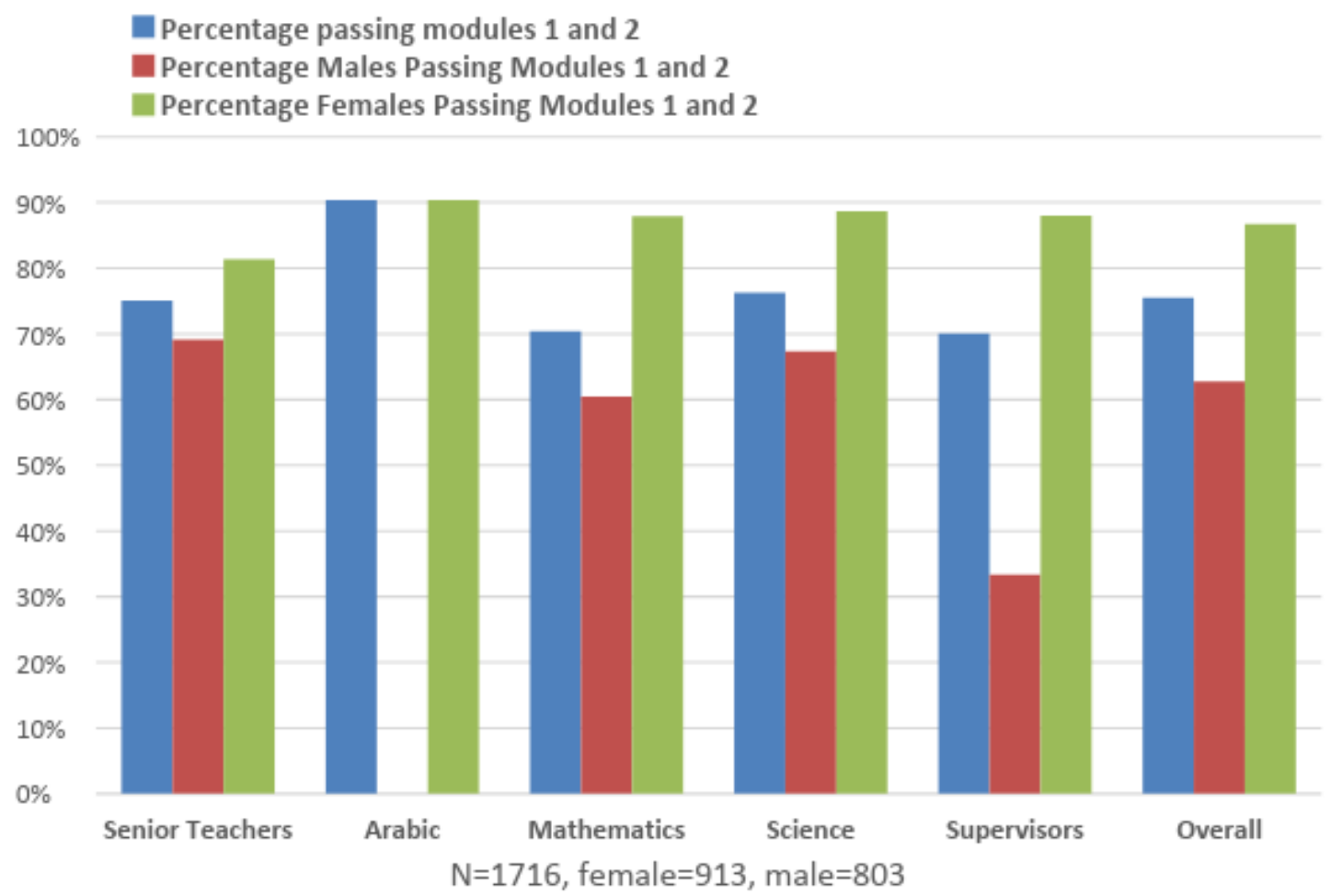

Figure 3: Module 1 and Module 2 Pass Rates by Gender and Programme (\%)

Impact is regarded as the crucial level in the ROI model since it is assumed that impact data provides more value to decision makers as it relates to the consequences of programme implementation (Philips and Philips 2007). The core of the SCPTT's work involves the TPD programmes, and the main task for evaluating the effects of programmes is (1) to find out whether it has produced 
any change in teachers' instructional practices, (2) to identify components of the professional development programme that facilitated or hindered implementation of instructional innovations (to identify best practices), and (3) to identify features (surrounding context) that facilitate or hinder teachers implementing instructional innovations (cf. Saunders 2013). In ideal setting, impact is measured after at least two years of practical implementation.

The first initiative carried out by the Centre to investigate the experienced impact of its programmes involves a small-scale qualitative study. This also helps provide insights to participants' application of the knowledge and skills learnt in training programme. A focus group technique was used to collect qualitative data to this study. The interview consists of twelve openended questions and two multiple-choice questions (Appendix). The group interviews were distributed to 114 random participants across the Centre's programmes. The researcher visited the schools to introduce the study and emphasised the need for their participation. The first interviews were conducted in 2015, targeted at three of the Centre's programmes, and involved sixteen senior teachers, seventeen regional supervisors and thirteen Arabic teachers. Two more meetings were organised for four programmes in April and May 2016 and involved six Arabic teachers, six senior teachers, sixteen mathematics teachers, twenty four new teachers and sixteen science teachers. The participants were provided with the questions prior to the discussion and at all meetings a member from the quality assurance and evaluation team acted as moderators.

The participants in all six programmes were asked to rate their performance before and after the training in percentages. Figure 4 shows a consensus among participants that their performance has improved. The overall improvement is approximately a bit higher than 10 percentage points. (The participants were also asked to estimate their confidence in their assessment. The confidence level is high, between $80-90$ percent depending on the group.)

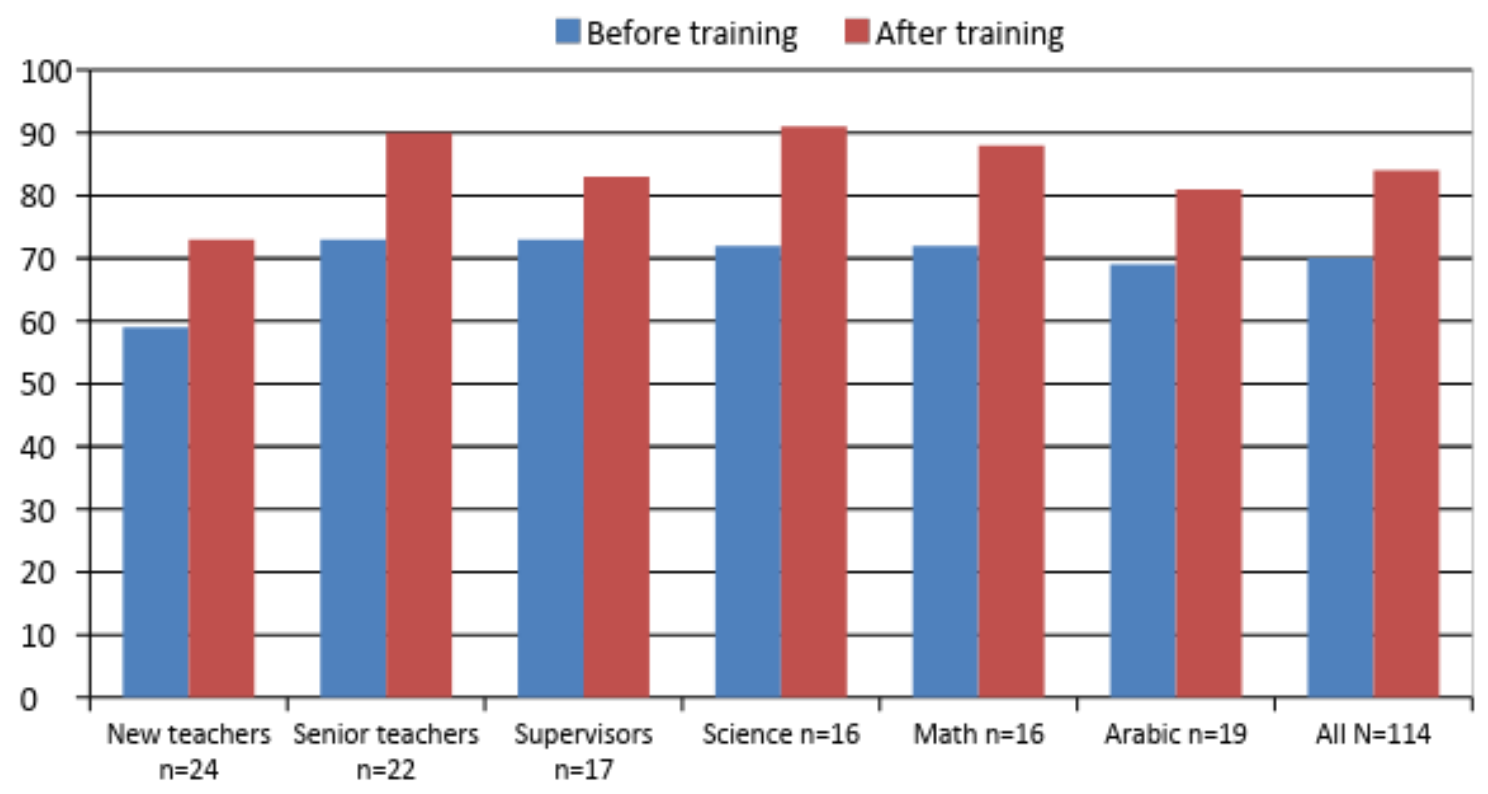

Figure 4: Participants' percentages estimation of their performance before and after training $(\%)$ 
The second part of this study was qualitative in nature (see appendix). The collection of the data was conducted through group interviews and the answers were coded. First question forms were distributed, and participants were given time to read the questions carefully. After a while questions were discussed thoroughly with participants, and they were then given time to complete the form. This process was repeated for each question. The questions were organised into the following five main themes: (1) suitability and appropriateness of the programmes, (2) the extent to which participants were able to acquire new knowledge and skills, (3) participants' application of the knowledge and skills acquired from the programme, (4) the factors enabling participants to apply and the barriers hindering application of the acquired knowledge and skills, and (5) sufficiency and quality of support for participants. The most crucial findings are presented in the following.

About $70 \%$ of the interviewees reported that the programmes are effective and practical. They are seen as representing a significant shift from the traditional type of in-service training and provide participants with valuable information and experiences that help them improve their performance in school. On the other hand, $29 \%$ of the participants argued that their school principals and supervisors did not provide them with appropriate support. They complained of a lack of resources, which prevented them from implementing some of the required skills, e.g. a participant claimed, that "the programme helps me to acquire new skills and knowledge and it enables me to improve my professional practice, however, more practical aspects like lessons modelling, micro-teaching and visiting classes during the face-to-face training need to be added".

Approximately $80 \%$ of the participants feel the programmes help them apply the acquired knowledge and skills in the workplace. A further $15 \%$ of participants say they could apply the acquired knowledge and skills with more support from their principals and supervisors and with the provision of appropriate resources and materials. Many participants suggested "that the Centre should work on strengthening communication with schools and supervision departments in the regions....and that school leaders need to be educated about the Centre's programmes and the tasks required for each module". Participants across all programmes believe that most of the skills taught are feasible for application but some from more remote regions (such as Dhara, Batinah North and Dhofar) were reluctant to apply due to a lack of instructional materials. Furthermore, many female participants stated that training in the Centre makes them feel "recognised" and "special" as the tasks of the workplace learning require them to apply new methods and share them with their colleagues. Consequently, one purpose of these tasks is to cascade and transfer learning to other teachers in participants' own school communities. These teachers state that "the training makes us feel special because we could sense that we are influencing our colleagues in the schools and the learning we deliver is making the change occur not only in teachers' behaviour and attitudes, we also could feel it among our students". The majority of males and females agree that the application of new ways of teaching helped improve students' enthusiasm, interest and readiness. It was not uncommon for the interviewed teachers to say that "once we start applying, we could see the difference and our 
students could see the change." On the other hand, most interviewed teachers across the whole country suffer from similar challenges and barriers in applying new teaching methods (see table 1 ).

Table 1: Programme enablers and barriers as seen by teachers (\%)

\begin{tabular}{|l|l|l|l|l|c|}
\hline Enablers & Region & $\%$ & Barriers & Region & $\begin{array}{l}\text { Most regions, especially } \\
\text { Batinah North }\end{array}$ \\
\hline School Principals & Most regions & 50 & Workload & 32 \\
\hline $\begin{array}{l}\text { Personal Desire and } \\
\text { Motivation }\end{array}$ & Most regions & 41 & Time constraints & Most regions & 21 \\
\hline Colleagues Support & Most regions & 36 & Network Coverage & $\begin{array}{l}\text { Most regions, especially } \\
\text { remote areas like Dhofar } \\
\text { and Wusta }\end{array}$ & Most Regions \\
\hline $\begin{array}{l}\text { Students' Readiness } \\
\text { and Interest }\end{array}$ & Most Regions & 25 & $\begin{array}{l}\text { Uncooperative } \\
\text { Colleagues }\end{array}$ & 18 \\
\hline Trainers Support & Most Regions & 22 & Lack of Resources & Most regions & 17 \\
\hline
\end{tabular}

The most often mentioned obstacles were workload and time constraints. Some argue that they suffer from a lack of instructional materials; some complain of uncooperative colleagues; others complain of technical problems such as poor internet coverage. Participants from most of the regions believe that these obstacles hinder the application. As one participant stated, "the Centre's programmes offer teachers and school leaders new teaching strategies, new visions and procedures. Unfortunately, many non-trained principals and supervisors do not see the value of SCPTT. We suggest the Centre should send the training programmes to schools prior to training and the SCPTT trainers and staff should conduct more school visits to brief staff about the Centre in order to guarantee their future support." (Appendix.)

Teachers clearly need more support from the Specialised Centre in their schools to enable application. They need to be provided with instructional materials from the governorates. One of the participants states: "We need more instructional materials to be provided at schools to enable us to apply". Another teacher argues that "most of us have the intention to apply but we lack support and we face some logistic constraints".

To ensure the positive impact of training the staff of SCPPT organises school field visits, in which the Centre's trainers conduct a short meeting with the school principal, senior teachers and supervisors to give a brief introduction about SCPPT, its role in teachers' professional development and the programmes. The Centre's trainers inform school principals, senior teachers and supervisors about their roles in supporting, observing, monitoring and following up with the participants and their students. Trainers also meet the participants in a coaching session to discuss a concrete lesson and the challenges they are facing in their workplace. Finally, the trainers fill a report template about the visit and send it to the Quality Assurance team, which collects the reports for further analyses. 


\section{Conclusions}

Until very recently, professional development in Oman relied on "a cascade approach" and most of the programmes were of short-term duration. Sporadic workshops for teachers were delivered regionally, in the governorates. Some of the workshops were delivered by taking teachers away from their schools for a week of continuous training, while others were organised on a day-off basis, with teachers being out of school once a week for an entire semester. Feedback from participants and trainers suggests that "block training" is more applicable for rigorous professional development. Besides provision of short in-service training courses, teachers' professional development was pursued by school inspections which were supportive in nature. (Etherton \& Al-Jardani 2009.) In previous decades, in-service training of teachers was governed and organised in a top-down manner. The top level decision makers were the planners and organisers of the training. Teachers' needs were not sufficiently met, and the impact of in-service training courses was not adequately examined. According to conclusions of Rajasekar's and Khan's $(2013,48)$ study, in Oman there is an urgent need to draw up a HRD and training framework for all government organizations that "will foster flexibility, creativity, team learning and collaboration among their employees."

In 2014, the Ministry of Education established a new organisation for professional development of teachers, the Specialised Centre for Professional Training of Teachers SCPTT, with a remit to plan, organise and provide training for all teachers in all eleven governorates in Oman. Compared to in-service training of previous decades, the new way of providing in-service training for teachers is systematic in provision and carefully monitored through a variety of methods. The ultimate goal of developing of teaching and the entire teacher profession is to raise the quality of learning and to improve student achievement. SCPPT is designed to support change through developed, managed decentralisation with increasing prominence on enabling research and collaboration among teachers. (Ministry of Education 2014.)

To improve student outcomes and build the capacity in teachers' skills and knowledge, the Ministry of Education has estimated that all educators must dedicate at least ten percent of their working time to professional development. It is also in the Ministry's policy that teachers' skills and confidence can be raised by encouraging teachers to take greater responsibility for their own development. In circumstances like Oman with heterogeneous quality of teaching force, TPD is a continuous long-term process with participants being step by step committed to their own professional growth. The idea of Omani TPD is that teachers are encouraged to bring new attitudes, knowledge and skills to their workplace for the development school community at large (see AlBusaidi \& Tuzlukova 2014). Eventually, development needs will be addressed through professional learning communities that produce their own resolutions and sustenance. The change that the Ministry of Education is looking for will be long-term, possibly taking as long as 20 years. The expectations towards the impact of the newly organised TPD on teacher quality and learning outcomes in Omani schools are high. It is expected that the effort on teacher professional development will bear fruit in enhanced level of skills in mathematics, science and literacy as assessed by TIMMS and PIRLS studies in the future. 
To ensure the quality of TPD a variety of tools and methods for examining the functioning and impact of the provided programmes are used in SCPPT. The ROI methodology is used to assess the effectiveness of the Centre's programmes. The ROI is a systematic approach that has five defined levels. Reaction and learning levels are measured regularly through an online questionnaire and some tailored activities in the face-to-face and online learning. The results have shown a positive reaction and satisfaction from all participants across all programmes. Application level is measured through activities for the workplace learning. Participants are required to complete the assignments, write a report or a case study which are submitted to the trainers at the Centre. These assignments are assessed and then moderated by experts (from UCL). High pass rates have been achieved for the first three levels. However, pass rates vary according to gender: female teachers pass the modules more likely than their male colleagues. There may be various reasons for this gender difference, but almost everything education related in Oman has "a gender effect": girls do better in school and studies, and female teachers are more strongly dedicated to their profession than men.

Besides using the ROI approach, the impact of training is examined and followed by several methods: analysing statistics on training programmes, conducting questionnaires, interviews, and lesson observations. In this article we have described results from focus group interviews which aimed to examine the satisfaction of participants as well as the application of newly acquired skills and practices in work context. Findings show a consensus of positive feedback from the participants. The majority agree that the programmes are useful and help them change their perspectives and develop their teaching practice. According to interviews programmes have provided the participants with new visions, strategies and attitudes towards teaching and learning. Not only improving practical skills is important in Omani context (cf. "reality shock") but attitudinal change may be even more important aim for TPD in long run. Professional growth is a gradual process. According to Guskey (2002) the change proceeds from skills to attitudes: if participants are able apply the knowledge and skills acquired from training, their attitudes and values tend to change.

\section{Directions for Future Research}

Change in skills of teachers is necessary but not sufficient factor to make practices and pedagogies change as well. Applying new skills and pedagogies often implies a radical change in established practices and ways of thinking in school culture with unquestionable elements due to long traditions. Furthermore, e.g., in English language teaching there are sensitive cultural and political issues involved (Al-Issa, 2005a; 2000b; 2007). Results from interviews reveal that teachers encounter a variety of obstacles in schools when trying to make use of what they have learned in TPD programmes. Many teachers reported that they do not get the enough support from their principals, supervisors, and colleagues. It is, therefore, still a work in progress, with participant responses indicating that additional support is needed in schools and the governorates, and that SCPTT staff and trainers need to improve communication with school leaders about the nation-wide TPD efforts. This observation brings us to the issue of further research needs in TPD and school 
system: in order to be able to make the change in schools, better understanding on obstacles for implementing new practices in schools and how to overcome them is needed.

With the exceptional position in country's TPD the Specialised Centre for Professional Training of Teachers has a good chance to encourage and cultivate a national professional educational dialogue, debate and collaboration through face-to-face activities and through the collaborative tools in the online Learning Platform. The platform includes the facility for teachers to share ideas, resources and good practices. The platform would be also useful for gathering experiences and findings related to obstacles of implementing new pedagogical methods and skills in every day school work. Traditional norms and established practices are not easy to replace in a hierarchical society (Al-Azri 2013). However, the educational dialogue may raise awareness amongst educators, students, parents and the wider community on the forms and contents of education and the needs of future society.

\section{References}

Al Balushi, S. and Griffiths, D. (2013). The School-Education System in Oman, in Donn, G., and Al Manthri, Y. (eds.) Education in the Broader Middle-East: borrowing a baroque arsenal. Oxford: Symposium Books, 107-125.

Al Kharusi, B., and B. Atweh. (2008). Civic Participation and Educational Reform in the Sultanate of Oman. Accessed June $15 \quad 2017$. http://oneworldripples.com/uploads/3/5/1/5/ 35158413/alkarusi_atweh_2008_aare.pdf

Al Lamki, N. (2009). The Beliefs and Practices Related to Continuous Professional Development of Teachers of English in Oman. Phd diss. University of Leeds. http://etheses.whiterose. ac.uk/id/eprint/2146

Al-Lamki, S. (2002). Higher Education in the Sultanate of Oman: The challenge of access, equity and privatization. Journal of Higher Education Policy and Management, 24 (1), 75-86, DOI: 10.1080/13600800220130770

Al Shabibi, A. (2013), Omani English Language Teachers' First Year in the Classroom. PhD Thesis in TESOL. University of Leeds.

Al Shabibi, A. \& Silvennoinen, H. (2017). Challenges in Education System Affecting Teacher Professional Development in Oman. Athens Journal of Education, 5(3), 261-282. http:// www.athensjournals.gr/education/2018-5-3-3-Al-Shabibi.pdf

Al-Azri, K. (2013). Social and Gender Inequality in Oman. The power of religious and political tradition. London: Routledge.

Al-Bushaidi, S., \& Tuzlukova, V. (2014). Local Perspectives on Teacher Professional Development: Targeting Policy and Practice. Asian journal of Management Sciences $\mathcal{E} \quad$ Education, 3(4), 74-84. http://www.ajmse.leenaluna.co.jp/AJMSEPDFs/Vol.3(4)/ AJMSE2014(3.4-05).pdf

Alexander, E. R. (2002). The Public Interest in Planning: From Legitimation to Substantive Plan Evaluation. Planning theory, 1(3), 226-249. http://journals.sagepub.com/doi/pdf/ 10.1177/147309520200100303

Al-Issa, A. (2005a). The Role of English Language Culture in the Omani Language Education System: An Ideological Perspective. Language, Culture and Curriculum, 18(3), 258-270. https://doi.org/10.1080/07908310508668746

Al-Issa, A. (2005b). The Implications of the Teacher Educator's Ideological Role for the English Language Teaching System in Oman. Teaching Education, 16(4), 337-348. https:// doi.org/10.1080/10476210500345656 
Al-Issa, A. (2007). The implications of implementing a 'flexible' syllabus for ESL policy in the Sultanate of Oman. RELC Journal, 38(1), 199-215. https://doi.org/10.1177/ 0033688207079693

Allen, C., and W. L. Rigsbee (2000). Oman Under Qaboos: From Coup to Constitution, 1970-1996. London: Frank Cass.

Canedcom International. (2004). Final Report for Evaluation of Cycle One Basic Education. Tender No. 15/2003. Muscat: Ministry of Education.

Chapman, D.W. \& Miric, S.L. (2009). Education quality in the Middle East. International Review of Education 55, 311-344. http:// www.jstor.org/stable/40270085

De Leon, A. \& Chough, K. (2013). Analysis of mixed data. 1st ed. Boca Raton, FL: CRC Press.

Education Council. (2012). The Most Remarkable Projects Developed by The Education Council. Sultanate of Oman. https://educouncil.gov.om/downloads/5HsT4BW532Q3.pdf

Etherton, S. \& Al-Jardani, M. (2009). Recent Developments in In-Service Language Teacher Education in Oman. In Atkins, J. Lamb, M. \& Wedell, M. (eds.) International Collaboration for Educational Change: The BA Project. Muscat: Ministry of Education, 191-200.

Goode, K., Kingston, T., Grant, J. \& Munson, L. (2010). Assessment for Learning. EFTO Voice, 12(3), 21-24.

Gray, D. E. (2011). Doing Research in the Real World, 2nd ed. Los Angeles: Sage.

Griffin, G.A. (1983). Introduction: The Work of Staff Development. In Griffin, G.A. (ed.) Staff Development, Eighty Second Yearbook of the National Society for the Study of Education. Chicago: University of Chicago Press, 1-12.

Guskey, T. R. (2002). Professional Development and Teacher Change. Teachers and Teaching, 8(3), 381-391. https:// doi.org/10.1080/135406002100000512

Harrison, R. (2003). Learning \& Development. London: Chartered Institute of Personnel and Development.

Jones, C. (2005). Assessment for Learning. London: Learning and Skills Development Agency.

Kelle, U. \& Erzberger, C. (2011). Qualitative and Quantitative Methods: Not in Opposition. In Flick, U., von Kardorff, E. \& Steinke, I. (eds.) A Companion to qualitative research. London: Sage Publications, 172-177.

Looney, R. (2009). The Omani and Bahraini Paths to Development Rare and Contrasting Oilbased Economic Success Stories. Helsinki: UNU World Institute for Development Economics Research UNU-WIDER.

Martin, M. O., Mullis, I. V. S. \& Foy, P. (2008). TIMSS 2007 International Science Report: Findings from IEA's Trends in International Mathematics and Science Study at the Fourth and Eighth Grades. Chestnut Hill: TIMSS \& PIRLS International Study Center, Boston College.

Martin, M. O., Mullis, I. V. S., Foy, P. \& Stanco, G.M. (2012). TIMSS 2011 International Results in Science. Chestnut Hill: TIMSS \& PIRLS International Study Center, Boston College.

Ministry of Education. (2008). Inclusive Education in the Sultanate of Oman: National Report of the Sultanate of Oman. Inclusive Education: The Way of the Future. Muscat: Ministry of Education. http://www.ibe.unesco.org/National_Reports/ICE_2008/oman_NR08.pdf

Ministry of Education. (2009). Towards a Sustainable World: Focus on Education for Sustainable Development in Oman. World Conference on Education for Sustainable Development-Moving into Second Half of the UN Decade. Bonn: UN.

Ministry of Education. (2014). Centre Information. Second edition. Muscat: The Specialised Centre for Professional Training of Teachers. 
http://havasapps.com/test/moe/wpcontent/uploads/2016/07/TT_Information_E.pdf

Ministry of Education. (2016a). Annual Educational Statistics Book. Issue 46. Muscat: Ministry of Education.

Ministry of Education. (2016b). Oman education framework for excellence. Draft [unpublished]. Muscat: Ministry of Education.

Mullis, I. V. S., Martin, M. O. \& Foy, P. (2008). TIMSS 2007 International Mathematics Report: Findings from IEA's Trends in International Mathematics and Science Study at the Fourth and Eighth Grades. Chestnut Hill: Boston College.

Mullis, I. V. S., Martin, M. O., Foy, P. \& Arora, A. (2012). TIMSS 2011 International Results in Mathematics. Chestnut Hill: TIMSS \& PIRLS International Study Centre, Boston College.

Mullis, I. V. S., Martin, M. O., Foy, P. \& Drucker, K.T. (2012). The PIRLS 2011 International Results in Reading. Chestnut Hill, MA: TIMSS \& PIRLS International Study Centre, Boston College.

Mullis, I. V. S., Martin, M. O., Foy, P. \& Hooper, M. (2016a). TIMSS 2015 International Results in Mathematics. Chestnut Hill: TIMSS \& PIRLS International Study Centre, Boston College.

Mullis, I. V. S., Martin, M. O., Foy, P. \& Hooper, M. (2016b). TIMSS 2015 International Results in Science. Chestnut Hill: TIMSS \& PIRLS International Study Centre, Boston College.

New Zealand Education Consortium. (2013). Evaluation of School System in Oman. Muscat: Ministry of Education.

Philips, P. P. \& Philips, J.J. (2007). The value of learning: How Organizations Capture Value and ROI and Translate them into Support, Improvements and Funds. San Francisco: Pfeiffer.

Pritchett, L. (2013). The Rebirth of Education: Schooling Ain't Learning. Washington: Centre for Global Development.

Punch, K.F. (2009). Introduction to Research Methods in Education (1st ed.). London: Sage.

Rajasekar, J. \& Khan, S. (2013). Training and Development Function in Omani Public Sector Organizations: a critical evaluation. Journal of Applied Business and Economics, 14(2),

$37-52$. https:/ / search.proquest.com/docview/1450019470?accountid=14774

Ryan, R. M. \& Deci, E.L. (2000). Self-determination theory and the facilitation of intrinsic motivation, social development and well-being. American Psychologist, 55(1), 68 78.

Saunders, R. (2013). The role of teacher emotions in change: Experiences, patterns and implications for professional development. Journal of Educational Change, 14(3), 303-333. https:/ / doi.org/10.1007/s10833-012-9195-0

United Nations. (2002). Arab human development report 2002. United Nations Development Program (UNDP). New York: United Nations. hdr.undp.org/sites/default/files/rbas_ahdr2002_en.pdf

Weiss, H. (2006). From the director's desk. The Evaluation Exchange. Harvard Family Research, Harvard Graduate School of Education, 11(4), 1.

World Bank (2012). Education in Oman: The Drive for Quality. Washington D.C: World Bank.

http://documents.worldbank.org/curated/en/280091468098656732/Mainreport

Wyatt, M. (2013). Motivating teachers in the developing world: Insights from research with English language teachers in Oman. International Review of Education, 59, 217-242. https://doi.org/10.1007/s11159-013-9358-0 


\section{Appendix: Data collection form [TRANSLATED FROM ARABIC]}

Ministry of Education, Directorate General of Human Recourse Development, Evaluating

Training Department

Summative Evaluation form of a Training Program (to be filled by the Participants at the end of the training program)

Name of Program:

Program time (starts)

.(ends)

Venue:

Implemented by Department of:

Name of participant (optional)

Gender: Male ( )

Female ( )

Expressing your frank and direct opinion when answering the following questionnaire is helpful to us in developing the training programs.

\begin{tabular}{|c|c|c|c|c|c|c|}
\hline & \multirow[t]{2}{*}{ Statements } & $\begin{array}{l}\text { Totally } \\
\text { agree }\end{array}$ & Agree & Neutral & Disagree & $\begin{array}{l}\text { Totally } \\
\text { disagree }\end{array}$ \\
\hline & & 5 & 4 & 3 & 2 & 1 \\
\hline \multicolumn{7}{|c|}{ Administrative organisation } \\
\hline 1 & Suitability of program date & & & & & \\
\hline 2 & Suitability of training rooms & & & & & \\
\hline 3 & Suitability of training services & & & & & \\
\hline 4 & Support from organizers & & & & & \\
\hline \multicolumn{7}{|c|}{ The programme content } \\
\hline 5 & $\begin{array}{l}\text { This program contributes to developing my current } \\
\text { profession }\end{array}$ & & & & & \\
\hline 6 & It meets my expectations & & & & & \\
\hline 7 & Appropriateness of training materials & & & & & \\
\hline \multicolumn{7}{|c|}{ The trainer } \\
\hline 8 & Mastery of delivering training materials & & & & & \\
\hline 9 & Use of different training strategies and instructions & & & & & \\
\hline 10 & Combining theoretical and practical aspects & & & & & \\
\hline 11 & Interacting with participants & & & & & \\
\hline \multicolumn{7}{|c|}{ Learning } \\
\hline 12 & Learning new skills & & & & & \\
\hline 13 & Acquiring new skills that help in workplace & & & & & \\
\hline 14 & Confident in the ability to apply & & & & & \\
\hline \multicolumn{2}{|c|}{ Overall average } & & & & & \\
\hline
\end{tabular}

In your opinion, what are the advantages of this program?

What are the most beneficial and applicable aspects to your work?

State any comments (weaknesses) regarding this program.

State any suggestions and recommendations that may help to develop the program.

\section{Your cooperation is appreciated}

